\title{
Role of Mindfulness-Based Cognitive Therapy in Alleviating Psychological Distress among Cancer Patients
}

\section{ABSTRACT:}

\author{
Fatemeh Abdollahi*, Prof. Mahmood S. Khan**
}

The purpose of this research was to examine the research literature on role of Mindfulness-Based Cognitive Therapy in alleviating psychological distress among cancer patients. World Health Organization and medical experts have expressed alarm about constantly the growing problem of cancer patients in the world. The researcher emphasize that the diagnosis of cancer not only has obvious physical ramifications for the patient, but also the trauma of a diagnosis produces psychological problem such as somewhat hardly manageable distress as well, and in the face of psychological stressors that negatively impact the patient's overall quality of life. The present study examined the results of various studies, for identifying the potential efficacy of MBCT as it could be applied to patients with cancer which presents psychological distress. Research on Mindfulness-Based Cognitive Therapy has supported the safety and effectiveness of this approach might be used with distress associated problems among cancer patients also other studies obtained results signified the effectiveness of this therapy while dealing with cancer patients showed significant impact in alleviating different type of problems associated with this disease. It suggests need for a comprehensive solution that combines medical, psychological, social and behavioral approach to this complex problem in initiating the distress of cancer patients.

Keywords: Mindfulness-Based Cognitive Therapy, Psychological Distress, Cancer

\section{INTRODUCTION}

In 2014, World Health Organization (WHO) examined that the cancer is a devastating disease for millions of people around the world. The incidence of cancer is steadily increasing and approximately 8.2 million people worldwide died from cancer in $2012,60 \%$ of world's total new annual cases occur in Africa, Asia and Central and South America, 30\% of cancers could be prevented. The WHO expected new world-wide cases of cancer to grow from 11.3 million in 2007 to 15.5 million in 2030, and the number of global cancer deaths to increase from 7.9 million to 11.5 million (a $45 \%$ increase), in this same period, influenced in part by an increasing and aging global population (WHO, 2009). This literature review considers whether the use of Mindfulness-Based Cognitive Therapy (MBCT) is a promising approach for solving psychological distress among cancer patients by responding to the such as questions:

*PhD Research Scholar, Department of Psychology, Aligarh Muslim University, Aligarh, India **Professor, Department of Psychology, Aligarh Muslim University, Aligarh, India

(C) 2014 F Abdollahi, M Khan; licensee IJIP. This is an Open Access Research distributed under the terms of the Creative Commons Attribution License (http://creativecommons.org/licenses/by/2.0), which permits unrestricted use, distribution, and reproduction in any Medium, provided the original work is properly cited. 
1. What is the Psychological distress in cancer Patients? 2. Is MBCT effective at treating psychological distress in cancer patients? 3. Is MBCT safe for cancer patients? 4. Is MBCT the best solution?

The experience of receiving a diagnosis of cancer is an intensely stressful experience for every person (Matchim \& Armer, 2007), and for their family members and support system. The initial reaction to cancer diagnosis is shock and confusion. Cancer might be associated with many potentially distressing thoughts that come to patients mind such as: Why me? Did I get cancer because of something I did? Did I cause it through being stressed? Or through my lifestyle? Am I making it worse through my worry? Similarly during remission, fears of recurrence might become overwhelming. Often such questions cannot be answered and trying to resolve them can lead to extensive rumination, a style of repetitive evaluative thought that has been shown to exacerbate and maintain low mood (Watkins, 2008), including in breast cancer patients (Segerstrom, Stanton, Alden, \& Shortridge, 2003). Meta-cognitive insight allows a new perspective on thinking that appears to disrupt rumination (Shapiro, Oman, Thoresen, Plante, \& Flinders, 2008) and allow potentially distressing thoughts or perceptions to be experienced without overwhelming distress.

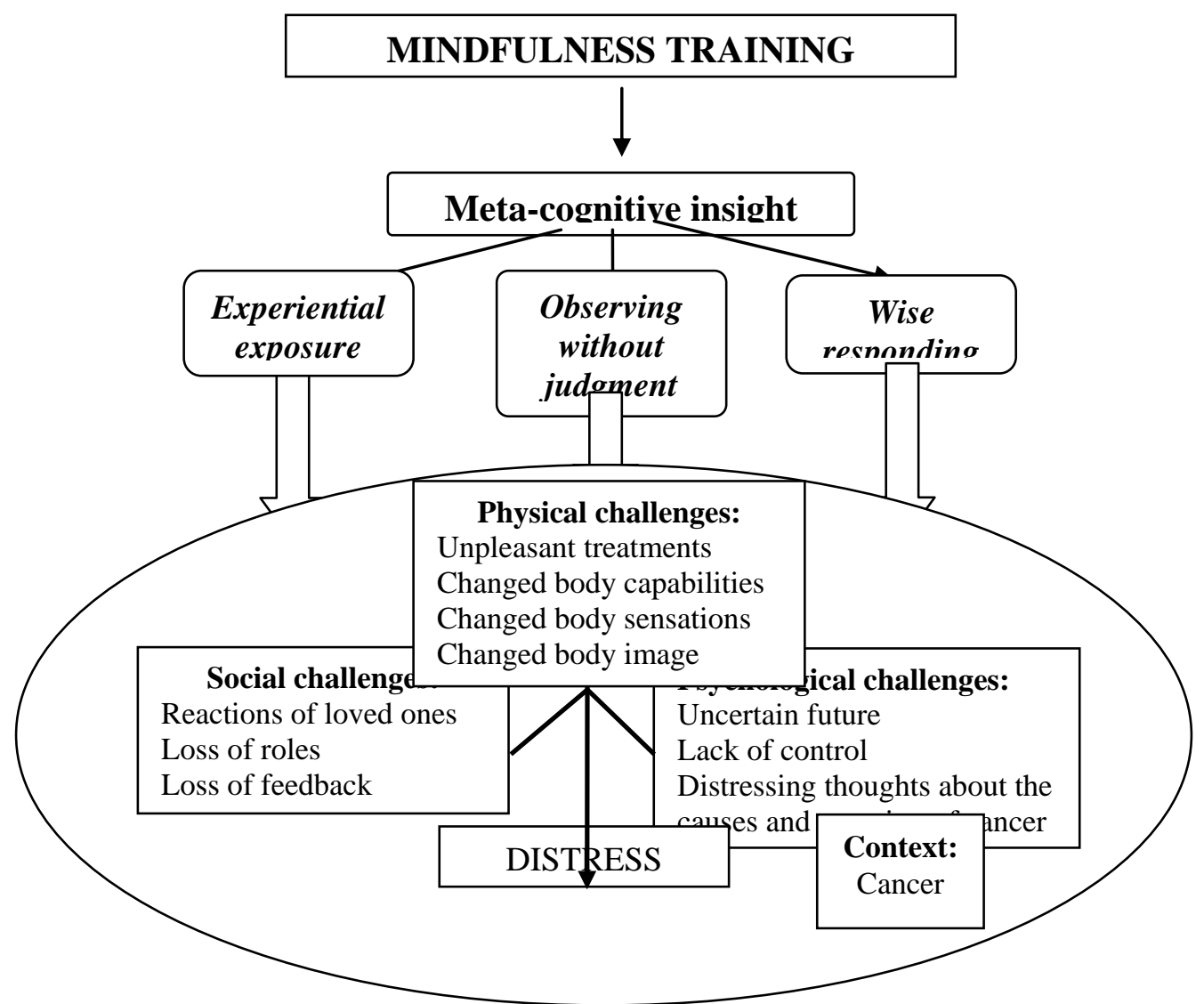

Figure 1. Diagram summarizing the challenges of cancer that might be targeted by purported mechanisms of mindfulness training (Emily Ruth Holden. 2010). 
According to McGregor BA and Antoni MH (2009) cancer patients are confronted with many stressors. In addition to the excessive physiologic stress caused by the disease and its treatment, many patients experience psychological stress regarding worries about diagnosis and prognosis, demanding treatments and treatment decisions, and disruption of ordinary life functions and roles.

As a psychological support the use of mindfulness based interventions has grown exponentially across health care, and particularly in the cancer area. Mindfulness has a 3,500 year history within Buddhist tradition, and has been widely embraced within Western healthcare over the past three decades. Mindfulness has been defined as non-judgmental, present-moment awareness and is comprised of two components: (1) self-regulation of attention so that there is focus on the current experience, and (2) adoption of a curious, open, and accepting orientation to the present (Bishop, Lau, Shapiro, Carlson, Anderson, Carmody, 2004). MBCT is skills-based group was developed by Segal, Williams and Teasdale, 1995 as a successful tool to treat chronic or recurrent depressive patients. It combines elements of Cognitive Behavioral Therapy (CBT) and the practice of mindfulness meditation into an eight week program that emphasizes the internal processes of depression-related recidivism (Segal, Williams \& Teasdale, 2002).

Table 1. Contrasting "Doing Mode" and "Being Mode"

\begin{tabular}{|l|l|}
\hline Doing Mode & Being Mode \\
\hline Goal oriented & $\begin{array}{l}\text { Focus on disconnection of thought and feeling from } \\
\text { goal-related action }\end{array}$ \\
\hline $\begin{array}{l}\text { Driven to reduce the gap between how things are and } \\
\text { how we would like them to be }\end{array}$ & $\begin{array}{l}\text { Focus is on "accepting" and "allowing" what is, } \\
\text { without any immediate pressure to change it }\end{array}$ \\
\hline $\begin{array}{l}\text { Attention is devoted to the narrow focus on } \\
\text { discrepancies between desired and actual states }\end{array}$ & Direct, immediate, intimate experience of the present \\
\hline
\end{tabular}

The diagnosis of cancer is a situation that understandably arouses a considerable amount of distress in patients. Mindfulness has been used to ease depression, anxiety and distress associated with this diagnosis (Kabat-Zinn, 2009).

\section{Cancer and Psychological Distress in People with Cancer}

The U.S. National Center for Health Statistic described chronic disease as a disease that persists for 3 months or more, that cannot be prevented by vaccines or cured by medication and does not resolve spontaneously, cardiovascular disease, chronic respiratory disease and diabetes, now cancer ranks as a chronic disease. Health damaging behavior particularly tobacco use, lack of physical activity and poor eating habits is a major and modifiable contributor to chronic diseases (WHO, 2010; Phillips \& Currow, 2010; Strong, Mathers, Leeder, Beaglehole, 2005). Cancer refers to a group of illnesses that result from cells in the body growing abnormally. These cells divide and produce new cells in an uncontrolled way that can spread throughout the body and cause damage to essential organs. Normal cells are constantly subject to signals that dictate whether the cell should divide, differentiate into another cell or die. Cancer cells develop a degree of autonomy from these signals, resulting in uncontrolled growth and proliferation. In this proliferation is allowed to continue and spread, it can be fatal. In fact almost, $90 \%$ of cancer related deaths are due to tumor spreading a process called metastasis (Momna \& Ventuse, 2010). 
Clinical factors such as stage and course of the disease, site of cancer, and medical and surgical treatment required have been shown to be of importance. Also, patient-related factors in the form of age-specific developmental life tasks that are threatened by the diagnosis, availability of social support and rehabilitative options have been suggested to influence psychosocial adjustment to cancer (Bottomley, 1997; Goldberg \& Cullen, 1985; Holland \& Rowland, 1990).

A cancer diagnosis can bring up a wide range of difficult emotions and significantly impact many areas of a person's life; it can have negative implications for psychological health, physical symptoms and may also adversely affect quality of life. Coping with a cancer diagnosis is known to be a traumatic event that can be related to declines in personal well-being and increases in distress. Effective coping is associated with a reduction of stress, depression, hopelessness or anxiety in response to a stressor. Many cancer patients experience psychological distress that distress is unlikely to be exclusively related to their disease or its treatment. Distress in cancer is defined as: "a multifactorial unpleasant emotional experience of a psychological (cognitive, behavioral, and emotional), social, and/or spiritual nature that may interfere with the ability to cope effectively with cancer, its physical symptoms and its treatment. Distress extends along a continuum, ranging from common normal feelings of vulnerability, sadness, and fears to problems that can become disabling, such as depression, anxiety, panics, social isolation, and existential and spiritual crisis."(National Comprehensive Cancer Network [NCCN] Clinical Practice Guidelines, 2007). Coping with a cancer diagnosis is known to be a stressful experience that can be related to declines in personal well-being and increases in distress. Researchers Trish Bartley and Ursula Bates (2012) have noted that Cancer is often associated with psychological distress as showed with the help of pie-diagram.

\section{Figure 2. Distress in oncology patients ${ }^{1}$}

The risk of psychological distress varies between different cancer patients and at different points in the cancer journey such as: characteristics of the individual and characteristics of disease and treatment. Middelboe T and his colleagues (1994) have noted while the symptoms of psychological distress in cancer patients may closely mirror those seen in other groups their etiology, characteristics, and

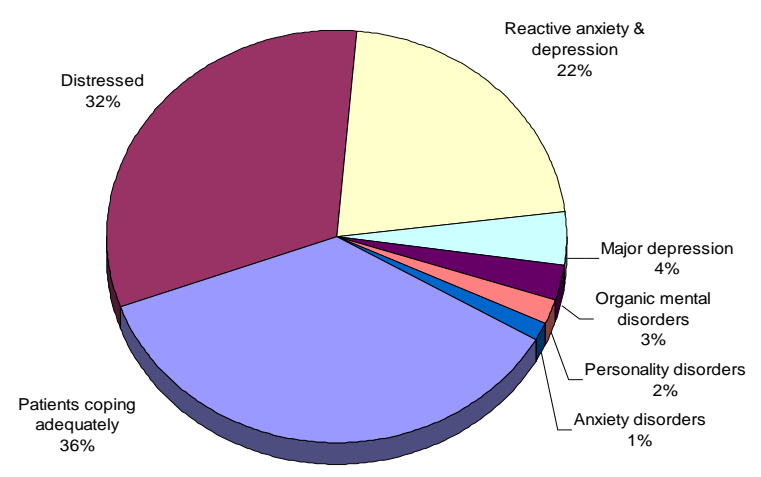
assessment and treatment needs may sometimes be quite different Cancer diagnosis and treatment is associated with a significant potential for psychological impact, so much in fact that some individuals will meet prevalence rate and criteria for anxiety, depression, or another mental health disorder (Van't, Trijsburg \& Duivenvoorden 1997; Ott, Norris, \& Bauer, 2006). Anxiety disorders occur frequently in patients

\footnotetext{
${ }^{1}$ Trish Bartley and Ursula Bates
} 
with cancer compared to the general population (Bodurka et al., 2000). Another most prevalent psychological distress in advanced and terminally ill palliative cancer care patients is depression (Akechi, Okuyama, Sugawara, Shima, Furukawa \& Uchitomi, 2006). Mc Daniel and his collages (1995) reported stressful life events, such as cancer diagnosis, are known to be related to increase depressive symptoms and fewer positive life experiences. According to Green AI, Austin CP (1993) depression has a biological basis in some cancers; Besides disease-related factors, lack of social support, social isolation, hopelessness and unstable financial status have also been found to contribute to the risk of depression in cancer patients (Balboni et al., 2007; Lorant, Croux, Weich, Deliege, Mackenbach, Ansseau, 2007). Feelings of hopelessness may play a special role in the distress of people with advanced cancer ( Breitbart et al., 2000); and Bair MJ et al (2003) examined that some symptoms of cancer, such as pain and fatigue, demonstrate a close relationship with distress and may need to be assessed and treated concomitantly with the distress itself. Fawzy (1997) have noted that a traumatic life experience, such as the diagnosis a life- threatening illness, forces an individual to alter future plans (Fawzy \& Fawzy, 1997). Having to reframe the future may result in anxiety, depression, confusion, and hopelessness. The majority of people experience anxiety and a significant degree of fear after having received a cancer diagnosis, including concerns about the future, fears about treatment side effects, changes in physical capacities, and changes in social roles (Speca, Carlson, Goodey,\& Angen, 2000). An understanding of the nature of the anxiety in cancer patient populations is important because abnormal anxiety is disruptive (Sherbourne, Wells \& Judd, 1996) and amenable to pharmacologic and psychological treatment (Sheard \& Maguire, 1999). Brennan (2004) argues that it is the need to attend to so many simultaneous challenges in different realms (physical, psychological and social) that can be overwhelming for cancer patients and create distress. Management of symptoms related to cancer and its treatment is an important part of cancer care, affecting patient quality of life, functional status, and completion of treatment. The vast majority of cancer patients experience one or more symptoms or side effects during treatment ( Barbera et al., 2010). The most common side effects are pain, fatigue, and psychological distress (Patrick et al., 2004).

\section{MBCT Effectiveness at Treating Psychological Distress in Cancer Patients}

Treatment of cancer is the series of interventions, including psychosocial support, surgery, and radiotherapy, chemotherapy that is aimed at curbing the disease or prolonging life considerably while improving the patient's quality of life (WHO, 2009).

This research was based on a psycho-educational intervention that incorporated mindfulness meditation skills which reviewed effectiveness of MBCT.

The research with the fundamental work of Zindel Segal, Mark Williams and John Teasdale (2002,2007) based on Jon Kabat-Zinn's Mindfulness-Based Stress Reduction (MBSR) program showing benefits of MBCT in the treatment of recurrent depression, stress, anxiety disorders, eating disorders, addiction and chronic illness (Kabat-Zinn, 1994; Grossman, Niemann, Schmidt 
\& Walach, 2004). Mindfulness-based therapeutic practices are receiving increasing empirical and clinical attention for their efficacy in treating various clinical disorders amongst a range of populations (Baer, Fischer, \& Huss, 2005; Bowen et al., 2006; Evans et al., 2008; Finucane \& Mercer, 2006; Ivanovski \& Malhi, 2007; Kabat-Zinn, 1982; Kabat-Zinn et al., 1992; Kristeller \& Hallett, 1999; Ma \& Teasdale, 2004; Marlatt, 2002; Ostafin \& Marlatt, 2008; Palmer \& Rodger, 2009; Speca, Carlson, Goodey, \& Angen, 2000; Teasdale et al., 2000; Williams, Duggan, Taylor, Crane, \& Fennell, 2006; Williams et al. 2008). In the last 10 to 15 years, some studies exploring the effectiveness of MBCT in depression (Dimidjian et al., 2010; Kenny \& Willimas, 2007; Ma \& Teasdale, 2004; Segal et al., 2002; Teasdale et al., 2000) and anxiety (Evans et al., 2008; Williams et al., 2008) in the general population and in primary care patients with active symptoms of depression and anxiety (Finucane \& Mercer, 2006). Mindfulness-based treatments have been utilized as a means to help increase an individual's awareness of emotional distress and maladaptive behavior (Baer, 2003). Mindfulness-based treatments may be helpful in treating individuals suffering from cancer (Matchim \& Armer, 2007). A recent meta analysis by Piet, Wurtzen \& Zachariae (2012) of 13 nonrandomized studies and 9 randomized controlled trials concluded there is positive evidence for the use of mindfulness-based interventions in reducing psychological distress in cancer patients. Research conducted by Brown and Ryan (2003) has demonstrated that trait based mindful awareness is associated with reduced psychological distress and improved well being in cancer patients. Researchers Melanie and his collages (2014) have explained, MBSR, as one of the few available psychosocial care programmes, contributes to the alleviation of lung cancer psychological distress. Findings of Stafford and colleagues (2013) provide preliminary support for the potential psychosocial benefits of MBCT in a heterogeneous group of women with cancer. Recent research shows that MBCT can effectively reduce symptoms of psychological distress in cancer patients, Sharplin et al (2010) noted the MBCT program appears to be an efficacious intervention for use among people affected by cancer that also experience symptoms of depression and anxiety. Foley and colleagues (2010) examined MBCT on outcomes of distress and quality of life among cancer patients. The intervention was modified for this population by including didactic information on cancer symptoms, making modifications for the length of the session depending on the fatigue of the individual, and including caregivers where needed. Compared to a wait-list control group, the individuals receiving MBCT showed reductions in depression, anxiety, and distress. MBCT is an effective treatment for chronic cancer-related fatigue (Lee \& Garssen, 2012).

\section{MBCT Safe for Cancer Patients}

Review of literature showing the effectiveness of MBCT for a variety of issues clients face in psychological distress. A successful stress reduction treatment is MBCT, which has been found to improve both physical and mental health outcomes (Grossman, Niemann, Schmidt \& Walach, 2004; Fjorback, Arendt, Ornbol, Fink \& Walach, 2011). Mindfulness was originally described as a stress reduction technique (Kabat-Zinn, 1982) and studies have reported that healthy participants who are trained in mindfulness report reductions in perceived stress scores in comparison to a control group (Warnecke, Quinn, Ogden, Towle \& Nelson, 2011). Mindfulness 
has been reported to reduce emotional reactivity (Erisman \& Roemer, 2010) and physical arousal response (Lush, Salmon, Floyd, Studts, Weissbecker \& Sephton, 2009) in response to acute stress. A review of research papers concluded that mindfulness-based interventions improved immune function and distress outcomes, with a small to moderate effect size, for people with cancer (Shennan, Payne \& Fenlon, 2011). Studies showed that MBSR improved the function of immune cells, displayed lower diurnal levels of blood serum cortisol and improved QoL outcomes in breast cancer patients (Shennan, 2011a, Witek-Janusek, Albuquerque, Chroniak, Chroniak, Durazo-Arvizu \& Mathews, 2008). MBCT may be able to improve the function of immune cells implicated in causing cancer. Some of the mindfulness practices encourage a state of physical arousal reduction (relaxation), these states of relaxation can reduce psychological and physiological arousal. If mindfulness skills reduce the frequency with which an individual enters a state of physiological arousal. This may be a mechanism for improving physical health status (Hamilton-West, 2011). Through meditation, breathing exercises and mindful-movement practices, mindfulness-based interventions aim to teach participants to become aware of and increase flexibility to switch between different cognitive modes of mind (Williams, 2010; Westbrook, Kennerley \& Kirk, 2011). While MBCT cancer groups focus on bodily sensations, this is a more significant that mindfulness exercises, such as the body scan, requiring participants to focus attention upon areas of the body affected by cancer can be challenging for some individuals also the body scan practice should proceed at a more moderate pace than in the standard classes. It is also recommended that initially the focus more general, and less specifically upon painful body sensations (Foley, Baillie, Huxter, Price \& Sinclair, 2010).

The study findings suggest that MBCT is a safe program for cancer patient with psychological distress and it has psychological benefits to cancer patients.

\section{MBCT the Best Solution}

The review study on the efficacy and safety on MBCT treatments of cancer patients raise the question of whether MBCT is the best solution for reducing mitigating the psychological distress in cancer patients. MBCT is a supportive and holistic psychotherapeutic service to patients with medical illnesses and related psychological distress that may improve coping through increased sense of control, relaxation, and distraction. Whilst mindfulness-based interventions are proving effective in ameliorating existing psychological and distress they are also beginning to be used in a preventative framework, giving people the skills they need to protect themselves from developing poor psychological and emotional health (Warriner, Williams, Bardacke \& Dymond, 2012).

The MBCT have clear costs for individual cancer patients, little information about longterm use, and uncertainty that they will yield significant reduction psychological distress.

\section{CONCLUSION}

In the last ten years mindfulness-based intervention has not only proven to be a feasible and acceptable intervention in cancer patients, but it also seems to be effective in reducing 
psychological distress. In general, the results suggest that MBCT is an acceptable and credible treatment that was associated with significant psychological distress symptoms, quality of life and physical health improvement. MBCT could be a helpful program in a large health care system.

Psychosocial interventions that effectively reduce the burden of disease associated with cancer are a priority in cancer care. MBCT originally developed to target ruminative processes associated with relapse to distress, has recently been modified for use in oncology. MBCT is one distinct method that has been proven effective against distress, depression, anxiety, and the symptoms that go along with them. It is a structured plan that helps people be in control of their thoughts and their reactions to them and with practice can thus eliminate the body's natural but costly stress reaction responses. Mindfulness-based intervention is frequently described in psycho-oncology literature, but little is known of the effectiveness of MBCT, more research should be conducted to ensure the efficacy of this treatment in helping professions to treat impact of cancer s. Professionals, cancer patients, their families, and agencies have much to gain from further research in this field. Understanding the limitations of psychological treatments for cancer, because of their weakness highlights the complexity of the cancer problem in the world and the need for opting psycho-oncologist and scientist search for other solutions along with medical treatment.

\section{REFERENCES}

1. Akechi, T., Okuyama, T., Sugawara, Y., Shima, Y., Furukawa, T.A., Uchitomi, Y. (2006) Screening for depression in terminally ill cancer patients in Japan. Journal of Pain Symptom Management, 31, 5-11.

2. Baer, R. A. (2003). Mindfulness training as a clinical intervention: A conceptual and empirical review. Clinical Psychology: Science and Practice, 10, 125-143.

3. Baer, R., Fischer, S., \& Huss, D. (2005). Mindfulness-based cognitive therapy applied to binge eating: A case study. Cognitive and Behavioral Practice, 12, 351-358. Retrieved from http://www.sciencedirect.com/science/journal/10777229

4. Bair, M.J., Robinson, R.L., Katon, W., Kroenke, K. (2003). Depression and pain comorbidity: a literature review. Archives of Internal Medicine, 163(20), 2433-2445.

5. Balboni, T.A., Vanderwerker, L.C., Block, S.D., Paulk, M.E., Lathan, C.S., Peteet, J.R., et al. (2007). Religiousness and spiritual support among advanced cancer patients and associations with end-of-life treatment preferences and quality of life. Journal of Clinical Oncology, 25, 555-560.

6. Barbera L, Seow H, Howell D, et al. (2010). Symptom burden and performance status in a population-based cohort of ambulatory cancer patients. 116(24), 5767-76.

7. Bishop SR, Lau M, Shapiro S, Carlson L, Anderson ND, Carmody J. Mindfulness: A proposed operational definition.(2004). Clin Psychol Sci Pract, 11(3):230-41.

8. Bodurka-Bevers D, Basen-Engquist K, Carmack CL, Fitzgerald MA, Wolf JK, de Moor C, et al. (2000) . Depression, anxiety, and quality of life in patients with epithelial ovarian cancer. Gynecol Oncol, 78,302-308. 
9. Bottomley, A. (1997). Psychosocial problems in cancer care: a brief review of common problems. J Psychiatr Ment Health Nurs, 4, 323-31.

10. Bowen, S., Witkiewitz, K., Dillworth, T., Chawla, N., Simpson, T., Ostafin, B., Larimer, M., Blume, A., Parks, G., \& Marlatt, A. (2006). Mindfulness meditation and substance use in an incarcerated population. Psychology of Addictive Behaviors, 20(3), 343-347. doi: 10.1037/0893164X.20.3.343

11. Breitbart W, Rosenfeld B, Pessin H, et al. (2000) Depression, hopelessness, and desire for hastened death in terminally ill patients with cancer. JAMA, 284(22):2907-2911.

12. Brennan, J. (2004). Cancer in context. Oxford, Oxford University Press.

13. Brown, K. W., \& Ryan, R. M. (2003). The benefits of being present: mindfulness and its role in psychological well-being. Journal of Personality \& Social Psychology, 84(4), 822-848.

14. Dimidjian, S., Kleiber, B., \& Segal, Z. (2010). Mindfulness-based cognitive therapy. In Kazantzis, N., Reinecke, M., Dattilio, F., \& Freeman, A. (Eds.), Cognitive and Behavioral Theories in Clinical Practice (pp. 307-330). New York: The Guilford Press.

15. Emily, R.H. (2010). Mindfulness and cancer: A literature review and empirical study (Doctoral dissertation), The University of Birmingham.

16. Erisman, S. M. \& L. Roemer, (2010) A preliminary investigation of the effects of experimentally induced mindfulness on emotional responding to film clips. Emotion, 10, 72-82.

17. Evans, S., Ferrando, S., Findler, M., Stowell, C., Smart, C., \& Haglin, D. (2008). Mindfulnessbased cognitive therapy for generalized anxiety disorder. Journal of Anxiety Disorders, 22, 716721. doi:10.1016/j.janxdis.2007.07.005

18. Fawzy, F.I. \& Fawzy, N.W. (1997). Psycho educational interventions and health outcomes. In R. Glaser \& J.M. Kiecolt-Glaser (Eds.), Handbook of human stress and immunity. San Diego, CA: Academic Press.

19. Finucane, A., \& Mercer, S. (2006). An exploratory mixed methods study of the acceptability and effectiveness of mindfulness-based cognitive therapy for patients with active depression and anxiety in primary care. BMC Psychiatry, 6(14), 1471-244X. doi: 10.1186/1471244X-6-14

20. Finucane, A., \& Mercer, S. (2006). An exploratory mixed methods study of the acceptability and effectiveness of mindfulness-based cognitive therapy for patients with active depression and anxiety in primary care. BMC Psychiatry, 6(14), 1471-244X. doi: 10.1186/1471244X-6-14

21. Fjorback, L. O., M. Arendt, E. Ornbol, P. Fink \& H. Walach. (2011). Mindfulness-based stress reduction and mindfulness-based cognitive therapy: a systematic review of randomized controlled trials. Acta Psychiatr Scand, 124, 102-119.

22. Foley, E., Baillie, A., Huxter, M., Price, M., \& Sinclair, E. (2010). Mindfulness-based cognitive therapy for individuals whose lives have been affected by cancer: A randomized controlled trial. Journal of Consulting and Clinical Psychology, 78(1), 72-79.

23. Goldberg, R.J. \& Cullen, L.O. (1985). Factors important to psychosocial adjustment to cancer: a review of the evidence. Soc Sci Med, 20, 803-7.

24. Green AI, Austin CP. Psychopathology of pancreatic cancer. (1993). psychobiologic probe Psychosomatics, 34:208 - 221. 
25. Grossman, P., Niemann, L., Schmidt, S., \& Walach, H. (2004). Mindfulness-based stress reduction and health benefits: A meta-analysis. Journal of Psychosomatic Research, 57(1), 3543. doi:10.1016/S0022-3999(03)00573-7.

26. Hamilton-West, K., (2011) Psychobiological Processes in Health and Illness. SAGE Publications, London.

27. Holland, J. \& Rowland, J. (1990). Handbook of psycho-oncology: Psychological care of the patient with cancer. Oxford University Press: New York.

28. Ivanovski, B., \& Malhi, G. (2007). The psychological and neurophysiological concomitants of mindfulness forms of meditation. Acta Neuropsychiatrica, 19, 76-91. doi: 10.1111/j.1601 5215.2007.00175.x

29. Kabat-Zinn, J. (1982). An outpatient program in behavioral medicine for chronic pain patients based on the practice of mindfulness meditation: Theoretical considerations and preliminary results. General Hospital Psychiatry, 4(1), 33-47. doi:10.1016/0163 8343(82)900275

30. Kabat-Zinn, J. (1994). Wherever you go there you are: mindfulness meditation in everyday life. Hyperion: New York.

31. Kabat-Zinn, J. (2009). Full catastrophe living: using the wisdom of your body and mind to face stress, pain, and illness. New York: Delta Trade Paperbacks.

32. Kabat-Zinn, J., Massion, A., Kristeller, J., Peterson, L., Fletcher, K., Pbert, L., Lenderking, W., \& Santorelli, S. (1992). Effectiveness of a meditation-based stress reduction program in the treatment of anxiety disorders. American Journal of Psychiatry, 149, 936-943. Retrieved from http://ajp.psychiatryonline.org/

33. Kenny, M. A., \& Williams, J. G. (2007). Treatment-resistant depressed patients show a good response to Mindfulness-based Cognitive Therapy. Behaviour Research And Therapy, 45(3), 617-625. doi:10.1016/j.brat.2006.04.008

34. Kristeller, J., \& Hallett, C. (1999). An exploratory study of a meditation-based interventionfor binge eating disorder. Journal of Health Psychology, 4, 357-363. doi: 10.1177/135910539900400305

35. Lee ML, Garssen B. Mindfulness-based cognitive therapy reduces chronic cancer-related fatigue: a treatment study. Psychooncology. 2012 Mar; 21(3):264-72. doi: 10.1002/pon.1890. Epub 2010 Dec 19. Author information: Helen Dowling Institute, Centre for Psycho-Oncology, Utrecht, The Netherlands.

36. Lorant V, Croux C, Weich S, Deliege D, Mackenbach J, Ansseau, M.(2007). Depression and socio-economic risk factors: 7-year longitudinal population study. Brit J Psychiat, 190:293-298.

37. Lush, E., P. Salmon, A. Floyd, J. L. Studts, I. Weissbecker \& S. E. Sephton. (2009). Mindfulness meditation for symptom reduction in fibromyalgia.

38. Ma, S., \& Teasdale, J., (2004). Mindfulness-based cognitive therapy for depression: Replication and exploration of differential relapse prevention efforts. Journal of Consulting and Clinical Psychology, 72(1), 31-40. doi: 10.1037/0022-006X.72.1.31

39. Marlatt, A. (2002). Buddhist philosophy and the treatment of addictive behavior. Cognitive and Behavioral Practice, 9, 44-50. doi:10.1016/S1077-7229(02)80039-6. 
40. Matchim, Y., \& Armer, J. M. (2007). Measuring the psychological impact of mindfulness meditation on health among patients with cancer: A literature review. Oncology Nursing Forum, 34(5), 1059-1066.

41. McDaniel, J. S., Musselman, D. L., Porter, M. R., Reed, D. A., \& Nemeroff, C. B. (1995). Depression in patients with cancer: diagnosis, biology, and treatment. Archives of General Psychiatry, 52, 89. Retrieved from http://archpsyc.ama-assn.org

42. McGregor BA, Antoni MH.(2009). Psychological intervention and health outcomes among women treated for breast cancer: a review of stress pathways and biological mediators. Brain Behav Immun, 23(2):159-166

43. Melanie PJ Schellekens, Desiree GM Hurk, Judith B Prins, Johan Molema, Rogier T Donders, Willem H Woertman, Miep A Drift and Anne EM Speckens.(2014). Study protocol of a randomized controlled trial comparing Mindfulness-Based Stress Reduction with treatment as usual in reducing psychological distress in patients with lung cancer and their partners.BMC Cancer, 14:3, Reviewed by http://www.biomedcentral.com/1471-2407/14/3

44. Middelboe T, Ovesen L, Mortensen EL, Bech P.(1994). Depressive symptoms in cancer patients undergoing chemotherapy: a psychometric analysis. Psychotherapy \& Psychosomatics, 61(3-4):171-177.

45. Momna Hejmadi \& Ventuse.(2010). Introduction to cancer biology, Publishing ApS, ISBN 97887-7681-478-6, 2010. P-6.

46. Network NCC. NCCN clinical practice guidelines in Oncology: Distress Management. (2007). http://www.nccn.org/professionals/physician_gls/PDF/distress.pdf.P6.

47. Ostafin, B., \& Marlatt, A.(2008). Surfing the urge: Experiential acceptance moderates the relation between automatic alcohol motivation and hazardous drinking. Journal of Social and Clinical Psychology, 27(4), 404-418.

48. Ott, M. J., Norris, R. L., \& Bauer-Wu, S. M. (2006). Mindfulness meditation for oncology patients: a discussion and critical review. Integrative Cancer Therapies, 5(2), 98-108.

49. Palmer, A., \& Rodger, S. (2009). Mindfulness, stress, and coping among university students. Canadian Journal of Counseling, 43(3), 198-212. Retrieved from http://www.ucalgary.ca/ucpress/Journals.html

50. Patrick DL, Ferketich SL, Frame PS, et al. (2004). Symptom management in cancer: pain, depression, and fatigue. National Institutes of Health State-of-the-Science Conference Statement. J Natl Cancer Inst Monogr ,(32): 9-16.

51. Phillips JL, Currow DC. Cancer as a chronic disease. Collegian. 2010,17:47-50

52. Piet J, Wurtzen H, Zachariae R.(2012). The effect of Mindfulness-Based Therapy on symptomps of anxiety and depression in adult cancer patients and survivors: a systematic review and meta-analysis. J Consult Clin Psychol, 80(6):1007-1020.

53. Segal ZV, Williams JMG, Teasdale JD. (2002) Mindfulness-based cognitive therapy for depression: A new approach to preventing relapse. New York: Guilford Press.

54. Segal, Z. V., Williams, J. M., \& Teasdale, J. D. (2002). Mindfulness-based cognitive therapy for depression: a new approach to preventing relapse. New York: Guilford Press. 
55. Segerstrom, S. C., Stanton, A. L., Alden, L. E., \& Shortridge, B. E. (2003). A multidimensional structure for repetitive thought: What's on your mind, and how, and how much? Journal of Personality and Social Psychology, 85(5), 909-921.

56. Shapiro, S. L., Oman, D., Thoresen, C. E., Plante, T. G., \& Flinders, T. (2008). Cultivating mindfulness: Effects on well-being. Journal of Clinical Psychology, 64(7), 840-862.

57. Sharplin GR, Jones SB, Hancock B, Knott VE, Bowden JA, Whitford HS. (2010). Mindfulnessbased cognitive therapy: an efficacious community-based group intervention for depression and anxiety in a sample of cancer patients.. Med J Aust, 6;193(5 Suppl):S79-82. PMID: 21542452.

58. Sheard T, Maguire P: The effect of psychological interventions on anxiety and depression in cancer patients: Results of two meta analyses. (1999). Br J Cancer, 80:1770-1780, 1999.

59. Shennan, C., S. Payne \& D. Fenlon, (2011) What is the evidence for the use of mindfulnessbased interventions in cancer care? A review. Psychooncology 20: 681-697.

60. Sherbourne CD, Wells KB, Judd LL. (1996). Functioning and wellbeing of patients with panic disorder. Am J Psychiatry, 153:213-218.

61. Speca, M., Carlson, L., Goodey, E., \& Angen, M. (2000). A randomized, wait-list controlled clinical trial: The effect of a mindfulness meditation-based stress reduction program on mood and symptoms of stress in cancer outpatients. Psychosomatic Medicine, 62, 613- 622. doi: 00333174/00/6205-0613

62. Stafford L, Foley E, Judd F, Gibson P, Kiropoulos L, Couper J.(2013). Mindfulness-based cognitive group therapy for women with breast and gynecologic cancer: a pilot study to determine effectiveness and feasibility. Centre for Women's Mental Health, Royal Women's Hospital.

63. Strong K, Mathers C, Leeder S, Beaglehole R. (2005). Preventing chronic diseases: how many lives can we save? Lancet, 366:1578-82.

64. Teasdale, J., Segal, Z., Williams, J., Ridgeway, V., Soulsby, J., \& Lau, M. (2000). Prevention of relapse/recurrence in major depression by mindfulness-based cognitive therapy. Journal of Consulting and Clinical Psychology, 68(4), 615-623. doi: 10.1037//0022-006X.68.4.615

65. Trish Bartley, Ursula Bates. (2011). Mindfulness-Based Cognitive Therapy for Cancer: Gently Turning Towards, Published Online: 17 NOV 2011, DOI: 10.1002/9781119960041.ch15, Copyright (C) 2012 Trish Bartley

66. Van't Spijker A, Trijsburg R, Duivenvoorden H.(1997). Psychological sequela of cancer diagnosis: A meta-analytical review of 58 studies after 1980. Psychosomatic Medicine, Vol 59(3), 280-293.

67. Warnecke, E., S. Quinn, K. Ogden, N. Towle \& M. R. Nelson, (2011) A randomised controlled trial of the effects of mindfulness practice on medical student stress levels. Med Educ 45: 381388.

68. Warriner, S., J. Williams, N. Bardacke \& M. Dymond, (2012). A mindfulness approach to antenatal preparation. Br. J. Midwifery, 20: 194 - 198.

69. Watkins, E. R. (2008). Constructive and unconstructive repetitive thought. Psychological Bulletin, 134(2), 163-206. 
70. Westbrook, D., H. Kennerley \& J. Kirk, (2011) An Introduction to Cognitive Behaviour Therapy: Skills and Applications 2nd Edition. SAGE Publications, London.

71. Williams, J. M., (2010) Mindfulness and psychological process. Emotion 10: 1-7.

72. Williams, J., Alatiq, Y., Crane, C., Barnhofer, T., Fennell, M., Duggan, D., Hepburn, S., \& Goodwin, G. (2008). Mindfulness-Based Cognitive Therapy (MBCT) in bipolar disorder: Preliminary evaluation of immediate effects on between-episode functioning. Journal of Affective Disorders, 107, 275-279. doi: 10.1016/j.jad.2007.08.022

73. Williams, J., Duggan, D., Crane, C., \& Fennell, M. (2006). Mindfulness-Based Cognitive Therapy for prevention of recurrence of suicidal behaviour. Journal of Clinical Psychology: In Session, 62(2), 201-210. doi: 10.1002/jclp.20223

74. Williams, M., Teasdale, J., Segal, Z., Kabat-Zinn, J. (2007). The mindful way through depresession: freeing yourself from chronic unhappiness. The Guilford Press: New York

75. Witek-Janusek, L., K. Albuquerque, K. R. Chroniak, C. Chroniak, R. Durazo-Arvizu \& H. L. Mathews, (2008) Effect of mindfulness based stress reduction on immune function, quality of life and coping in women newly diagnosed with early stage breast cancer. Brain Behave Immune 22: 969-981

76. World Health Organization. 2009. About cause-specific mortality and morbidity. Retrieved from http://www.who.int/features/qa/15/en/.

77. World Health Organization. 2014. About Cancer. Retrieved from http://www.who.int/cancer/en/.

78. World Health Organization: Chronic Diseases and Health Promotion. Accessed 20/6/2010 http://www.who.int/chp/en/ 